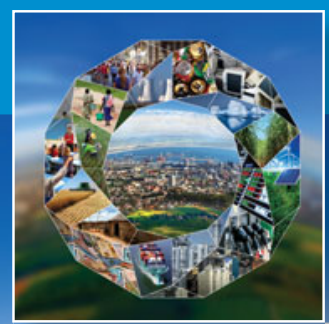

\title{
Materials for sustainable development
}

\author{
Martin L. Green, Laura Espinal, Enrico Traversa, and Eric J. Amis
}

Many technologies in the materials, manufacturing, energy, and water sectors that currently provide important benefits to humanity cannot continue indefinitely and must be directed toward a more sustainable path. In this article, we introduce the concept of sustainable development, discuss the critical roles that materials science plays in this field, and summarize the contents of the articles in this special issue of MRS Bulletin.

A society grows great when old men plant trees whose shade they know they shall never sit in.

-Greek proverb

This maxim demonstrates that sustainable development is not a new concept, at least according to its most popular definition: "Sustainable development is development that meets the needs of the present without compromising the ability of future generations to meet their own needs" (from the so-called Brundtland Commission Report, published in 1987).*,1 Why then has sustainable development come so much to the fore in the

\footnotetext{
* In speaking of "sustainable development," the Brundtland report referred to sustainable economic development. In this issue, we take a much broader view of sustainable development, including a range of activities that reflect the spirit of this famous pronouncement. Further, we understand the noun "sustainability" to be the asymptotically approachable, but ultimately unachievable, result of continual sustainable development. More on the Brundtland definition: It does not define sustainable development scientifically and requires that we know, or at least accurately estimate, what the needs of future generations will be. Had our Paleolithic ancestors taken Brundtland to heart, they might have carefully monitored their use of obsidian and flint and stockpiled such stones for future generations. Of course, the Stone Age did not end because humans ran out of stones, but because they found a better substitute, as our species always has.
}

past few decades? Perhaps it is the new buzzword due to growing concerns about the scale of the human impact on the planet. Indeed, the dramatic increases in global population that have occurred ever since the Industrial Revolution are expected to continue, and through the burning of fossil fuels to support the energy needs of this growing population, humankind has liberated a quantity of carbon (as carbon dioxide) in the past two hundred and fifty years that it took our planet about two hundred and fifty million years to sequester. That factor of a million - the price humankind unwittingly paid for the massive industrialization that enabled the advanced civilization many of us now enjoy - has shifted Earth's biosphere to a new equilibrium.

Every human endeavor is affected by the ramifications of sustainable development, because none of our material resources are infinite and only a few sources of energy (solar, wind, hydro, tidal, and geothermal) are sustainable. Sustainable development is a huge field that captures the concepts of environmental stewardship, materials management, green manufacturing, renewable and clean energy technologies, and water and air management under one tent. It is the process by which policies for continual improvements of the economy, environment, and society (the "triple bottom line"2) are guided by scientific analysis. The threefold nature of sustainable development is illustrated in Figure 1. Because the three components of the triple bottom line overlap, it is the nature of sustainable 


\section{LANDSCAPE • INTRODUCTION}

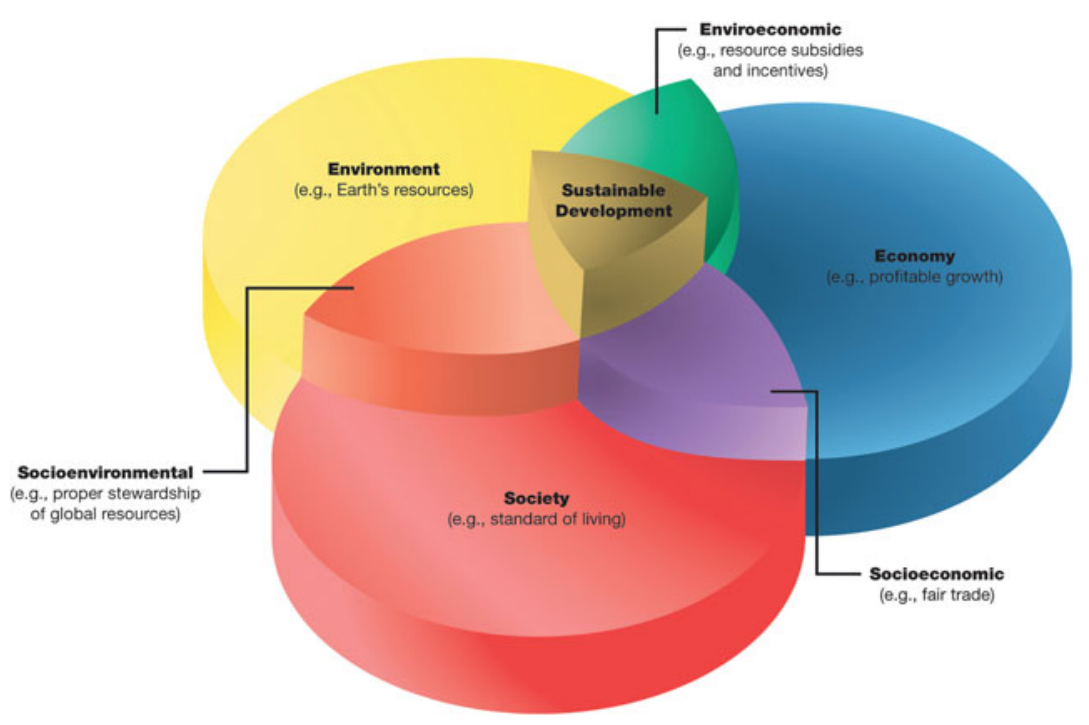

Figure 1. Sustainable development's "triple bottom line," which includes social, economic, and environmental aspects. Sustainable development exists when all three overlap.

development issues to be highly interconnected. Often, a benefit to one part of the bottom line is a deficit to another; a typical example is the marketing of fresh out-of-season produce. ${ }^{3}$ (See the sidebar for another perspective on the triple bottom line.) Sustainable development is thus ideally implemented through the development of scientific tools for full life-cycle assessment (measurements, standards, models, and data). Only quantitative analysis can determine whether the introduction of a change in a product or process represents a sustainable development.
It is important to view sustainable development as a process, a global kaizen (Japanese concept of the process of continuous improvement). Thus, although mentioning clean-coal technology in the context of sustainable development might seem contradictory, the process of reducing the environmental effects of burning fossil fuels, on which society will depend for at least the near future, while developing alternative sustainable energy sources to gradually replace them is bona fide sustainable development.

This special issue of MRS Bulletin explores the intersection of sustainable development and materials science. Materials have always been technology enablers; there would be no information age without silicon, no mobile phones without functional ceramics, no commercial aviation industry without high-strength aluminum alloys, and no skyscrapers without steel girders. Materials will continue to play the same role in sustainable development. Would it be possible to take advantage of the direct conversion of solar power to electricity if photovoltaic materials did not exist and were not efficient and manufacturable? In fact, sustainable development will not be possible without the full involvement of the materials community. This special issue of MRS Bulletin thus provides a materials-centric view of sustainable development, highlighting those areas in which materials science is expected to play a major role. Such areas include manufacturing of materials and products, transportation, infrastructure, energy and water resources, and education.

\section{The Kaya Identity}

One interesting way to look at the triple bottom line of sustainable development is through the Kaya identity. ${ }^{12,13}$ The Kaya analysis is a particularly apt framework for discussing sustainable development, as it is based on carbon dioxide emissions, a convenient figure of merit of human activity. ${ }^{\dagger}$ The Kaya identity is expressed as

$$
F=P\left(\frac{G}{P}\right)\left(\frac{E}{G}\right)\left(\frac{F}{E}\right)
$$

where $F$ is global carbon dioxide emissions, $P$ is global population, $G$ is the sum of global gross domestic products, and $E$ is global energy usage. Thus, $G / P$ is the global gross domestic product per capita, which can be thought of as "economic development or standard of living" and exists in the socioeconomic region of Figure $1 ; E / G$ is the energy intensity of the global gross domestic product, which can be thought of as "energy and resource efficiency" and exists in the enviroeconomic region of Figure $1 ; F / E$ is the carbon intensity of the global energy, which can be thought of as "sophistication of energy production" and exists in the socioenvironmental region of Figure 1. The Kaya analysis indicates that, to sustainably develop energy resources (i.e., lower carbon dioxide emissions), one can minimize $P$ (this is a political and social issue, outside the realm of science and technology) or reduce $G / P$ (this means a reversal of economic growth, which is anathema to the concept of sustainability). Therefore, the only paths forward are to reduce $E / G$ through demand reduction or to reduce $F / E$ through energy supply substitution.

† You can have lots of fun with the Kaya equation at www.wired.com/wired/st_formula.html. 
The links between sustainable development and materials are so obvious and basic that, paradoxically, they are often invisible to the users of advanced technologies. As technology enablers, materials are often in the background and are not perceived by end users as critical. When driving a modern automobile, for example, the owner enjoys its improved fuel economy but is often oblivious to the materials technologies (lightweight composites and alloys, electronic controls, high-density batteries, and so on) that made that improvement possible. Figure 2 shows some examples of such materials applications for sustainable development. This special issue is intended to bring the critical role of materials in sustainable development to the forefront, so that technologists, policy planners, and captains of industry can use this knowledge to define and plan the future roles of advanced materials in the sustainable-development arena.

Materials researchers and engineers have myriad opportunities to incorporate sustainable development into their work, and many already have. The immediate and direct connections between sustainable development and materials science include efficient use of materials (conservation, substitution, reuse, repurposing, recycling), materials life-cycle assessment (LCA) (see Figure 3), replacement materials (scarcity, resource availability, materials economics), energy (materials to support alternative energy technologies, to mitigate problems with fossil-fuel technologies, and to increase energy efficiency), mitigation of undesirable environmental impacts from technology and economic growth (corrosion, pollution, toxic waste), and water purification. Readers of this issue will no doubt find more topics to add to this list. Future MRS Bulletin issues and articles are anticipated to continue to address the individual topics represented in this issue, such as recycling or LCA methodology. This special issue follows an earlier one that dealt entirely with energy and energy-related materials. ${ }^{4}$

While putting this special issue together, we were struck by the fact that many of our contributors are not part of the materials community at large and do not typically attend the conferences that serve the materials community. Some are working at the periphery of the materials community as, for example, industrial ecologists and economists. ${ }^{5-7}$ Only when such experts and their outstanding work are integrated into the materials community, through enhanced collaboration, will this community be able to fully realize its role in sustainable development.

The greatest challenge to sustainable development might well be that of changing human behavior. Technology alone will not be the answer; governments, policy makers, and technologists will have to develop national and global policies, as discussed by Apelian in the first article in this issue. Further, he contrasts the closed loop of the natural ecosystem, where there is no "waste," with the open-loop nature of human society. As
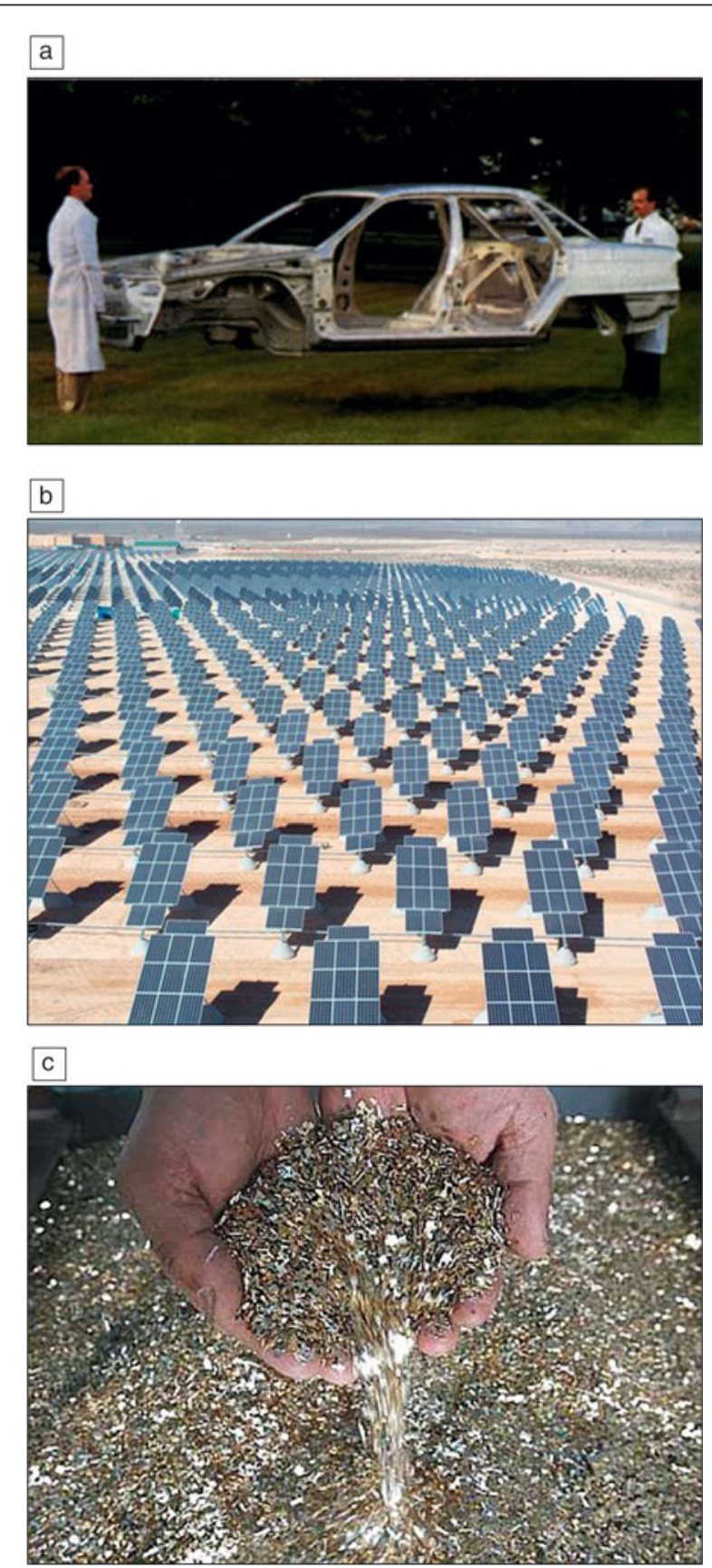

Figure 2. Sustainable developments in materials: (a) Lightweighting is an obvious strategy for all forms of transportation. (Image courtesy of the National Institute of Standards and Technology.) (b) Photovoltaic materials have the potential to be deployed on a large scale for the economical and sustainable generation of electrical power. (Image courtesy of New Energy Nexus.) (c) The recyclate stream from electronic waste, a component of "urban mining," can be richer in strategic elements than an actual mine. (Image courtesy of Star Publications.)

global population grows, the most important question might be not how many people Earth can support, but how many people Earth can support sustainably with an adequate standard of living. 


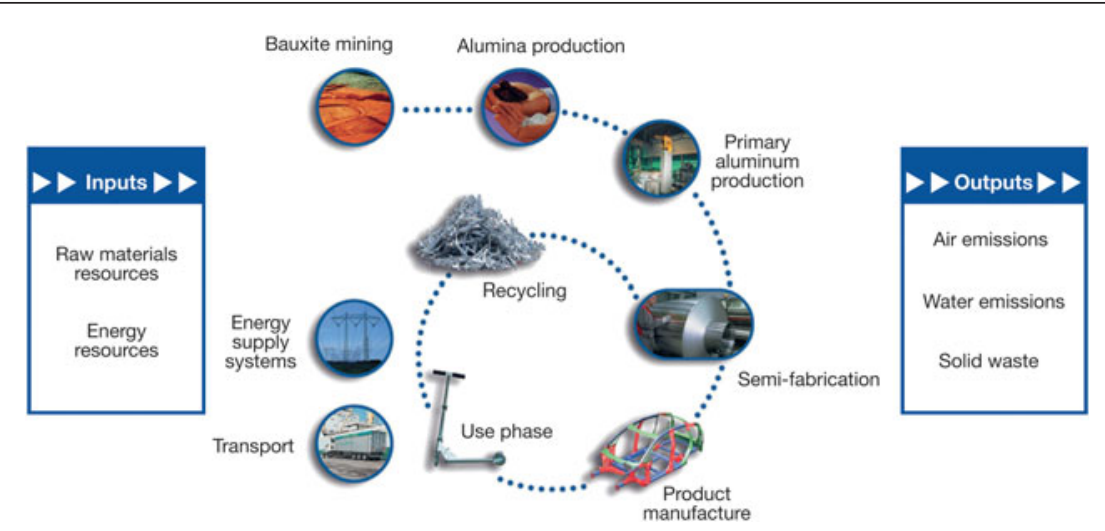

Figure 3. Life-cycle assessment methodology, as applied to aluminum products. In life-cycle assessment, all input and output energy and materials resources are taken into account for a given product or process, once its boundaries have been specified. (Image courtesy of the International Aluminium Institute.)

materials in products to be recycled, as pointed out in the article by Reuter and van Schaik. Thus, such models will incorrectly predict the recycling costs. For example, the recyclate streams will be very different for a car (large pieces of compressed metal) and a computer (fine particulates containing metals). Further, knowledge of the relative ease of "liberation" of the metals of interest in a given product can be used as feedback to design products that are more "recycle-friendly."

Industry is increasingly aware that sustainable development is not only a business opportunity but also a challenge; there is growing market demand for sustainable products, but regulatory standards can make these products difficult to develop economically. Poster et al. discuss how measurements, standards, and data can help industry meet the challenges of developing and intro-

Materials researchers now employ essentially the entire periodic table to enable the benefits of modern technology. However, reports of shortages of metals, for example, rare earths, are rife and have even been featured in the general press. Thus, as Graedel and Erdmann point out, it is reasonable to wonder about elemental resources, because material supply-chain analysis is key to sustainable manufacturing. However, supply assessment is not trivial, as data are often sparse. Graedel and Erdmann stress that materials scientists and corporate and government leaders must understand the complex issue of resource supply and create policies to deal with shortages; government-supported materials research programs for identifying substitutes for key elements is one example. Several other articles in this issue address specific materials resource issues, such as those by Konitzer et al. (turbine engine development), Hurd et al. (energy-critical elements), Englert et al. (nuclear materials), and Fthenakis (photovoltaic materials).

Whereas most grade-school students understand the value of recycling, applying a “one-size-fits-all” recycling strategy will not lead to optimal results, as discussed in the article by Gaines. If a material or product is reused, the direct environmental impact of its production might be reduced; however, the energy resources used to restore the item to a usable condition must also be taken into account. For example, recycling office paper reduces the cutting of timber but does not save fossil fuel, whereas combustion of this paper (a very clean fuel) can displace coal in power plants. Such determinations can be made using the LCA method, which is at the core of sustainable development and can assess the comprehensive carbon, material, and energy footprints of a product.

However, LCAs of durable, multimaterial goods such as batteries become much more complicated very quickly. Although many LCA models and corresponding codes exist, most do not take into account such complexities as the mechanical properties of ducing sustainable materials such as bio-based polymers and lead-free solders. An excellent example of the need for a standard is in bio-based feedstocks for the manufacture of chemicals. The polymer industry requires reliable measures of the true bio-based content in feedstocks, which can also contain petroleum-derived constituents. Because the ${ }^{14} \mathrm{C}$ content in ancient petroleum is much lower than that in feedstocks derived from recently living organisms, standards based on ${ }^{14} \mathrm{C}$ content have been developed to validate claims about bio-based products.

In the process of selecting materials for a new product design, industry has traditionally focused on cost, performance, and more recently carbon footprint. However, Ogunseitan and Schoenung point out that chemical toxicity is another important factor affecting sustainable development. Thus, they argue for a stronger integration of toxicity metrics in materials informatics databases. Without such data, product evolution can solve some problems but create others. The replacement of cathode ray tubes (CRTs) by liquid-crystal displays (LCDs) or plasma flatpanel displays (PDs) is a case in point. LCDs and PDs contain less lead than CRTs and, therefore, decrease the human-health toxicity potential. However, the presence of mercury in LCDs and copper in PDs significantly increases their ecological toxicity potentials at the end of the product lifetimes.

The transportation sector offers many opportunities for sustainable development, as the most energy-efficient means of travel depends on many factors and varies for different situations. In the United States, automobiles are predominant, although vehicle ownership is expected to expand greatly in China, India, and other developing countries in the near future. To support sustainable development of the transportation sector, automobiles must become more sustainable through lightweighting (see Figure 2a), enhanced fuel efficiency, and longer service use, and as Keoleian and Sullivan report, such trends are already underway. Ultimately, they conclude that sustainable mobility for a growing population of 7 billion people requires dramatic innovations by the materials and automotive industries, international commitments and policies for addressing 
greenhouse-gas emissions, and a more informed consumer base that understands basic sustainability concepts.

In all transportation sectors, lightweighting is an obvious path to reduce energy consumption in the use phase of the life cycle. However, as discussed by Duflou et al., the manufacturing and end-of-life phases of the product life cycle must also be taken into account when analyzing the total environmental impact. For example, a detailed LCA study of substituting carbon-fiberreinforced polymer (CFRP) for steel and aluminum structures in cars and airplanes found that CFRP has greater environmental impacts during manufacturing and end of life than the metals. However, the lighter-weight CFRP has a lower impact during use that accrues with each mile traveled. Thus, the sustainable impact is dependent on the lifetime of the vehicle, and there exists a "breakeven mileage" point beyond which use of CFRP has a lower overall impact than use of steel or aluminum.

Jet engines are subject to much more demanding performance standards than automotive engines. The list of materials available to aircraft engine designers 50 years ago was relatively limited compared to what it is today, and further, the jet engine market has continuously demanded increased efficiency. Konitzer et al. explain that efforts to increase engine efficiency through high-temperature operation have resulted in the use of elements that are, in general, scarcer than those for which they are being substituted (otherwise, they probably would have been used in the first place). Their article discusses the methodologies used to maintain a sustainable supply of one such element, rhenium. They conclude that the four-pronged approach of "reduce, revert, recover, and recycle" can conserve this element for use in achieving further efficiency improvements.

Materials demands for

[S] ustainable mobility for a growing population of 7 billion people requires dramatic innovations... our infrastructure, that is, the buildings, roads, pipelines, bridges, power lines, communications, canals, and waterways that people use on a daily basis without much thought, are substantial, as pointed out in the article by Heard et al. In addition to the large volume of material resources required (for example, each year the equivalent of $1 \mathrm{~m}^{3}$ of concrete is poured for every person on Earth), infrastructure construction and operation require large energy inputs and generate large pollution and waste flows. Improving the sustainability of infrastructure will require using materials, including recyclates and byproducts, more efficiently and designing and building for longer life.

With more than half of the world's growing population living in cities, a sustainable physical infrastructure is central to improving and maintaining a high quality of life. Concrete is the most important infrastructure material and, in fact, the most widely used manufactured material on the planet. Further, concrete is the most carbon-intensive material to process. Yet, even though forms of concrete were used in ancient Rome, questions are still being asked about the fundamental mechanisms of concrete formation and processing. The article by Van Vliet et al. provides an up-to-date perspective on the sustainability science of this miraculous "liquid stone." Their multiscale approach speaks to the belief that a more fundamental understanding of concrete will facilitate its optimization at several different length scales.

Energy production enjoys a central position under the sustainability tent. Thus, energy-related materials are essential to sustainable development, and the subject is discussed in a variety of articles in this issue. Hurd et al. make the case for energy-critical elements and isotopes, that is, those required for emerging sustainable energy sources that might encounter supply disruptions. Although rare-earth elements are often held up as the epitome of such critical materials, uranium and tellurium are also examples. An earlier article in this issue, that by Graedel and Erdmann, discusses possible supply limitations of a broader spectrum of elements for manufacturing technologies and explains that the existence of a natural resource does not guarantee that an element or material derived from it is readily obtainable.

Indeed, in their article on the complex relationship between materials and energy, Lubomirsky and Cahen point out that the availability of any material is determined not only by its crustal abundance but also by the amount of energy necessary for its recovery from ores. The vast majority of the energy produced on Earth is consumed in applications vital to ongoing societal needs, leaving perhaps only a few percent available in the short term for new materials technologies. Thus, production of new energy-critical materials cannot be increased rapidly, imposing severe restrictions on the rate of energy technology change.

The proper place for nuclear power in the energy mix has often been contentious and will likely continue to be so for the foreseeable future. Global opinions about the wisdom of expanding nuclear power generation vary widely; for example, Germany plans to phase out nuclear power, whereas neighboring France gets about $75 \%$ of its electricity from nuclear plants (in the United States, the number is about 20\%, and in Japan, before the Fukushima nuclear accident in March 2011, it was about $30 \%$ ). Issues of plant safety, weapons proliferation, and waste storage problems are important, but Englert et al. raise the more basic question of the sustainability of fissile nuclear energy by considering uranium and thorium resources in relation to different fuel cycles. They report that current identified resources can sustain only a two- to three-fold increase in nuclear capacity through the end of this century; further demands would necessarily involve the use of thorium and advanced fuel cycle technologies. Advanced (closed) fuel cycles generate large amounts of fissile materials and are thus problematic because of possible diversion for nuclear weapons (a nuclear device can be made with less than $10 \mathrm{~kg}$ of ${ }^{239} \mathrm{Pu}$ ).

Photovoltaic solar energy is touted as an important part of a global fix for increasing energy demand, although it still represents a very tiny fraction of the whole energy infrastructure, providing less than $1 \%$ of the electricity in the United States in 2010, for example. ${ }^{8}$ An important aspect of the photovoltaic power industry, the need for sustainable growth at much higher energy production levels, is discussed in great 
detail in the article by Fthenakis, who reports that photovoltaics are following a path of cost reduction and market growth that should enable this technology to become a major player in global energy markets, providing terawatts of renewable energy. However, at the very highest levels of market penetration, the sustainability of the industry hinges on concerns about cost, resource availability, and potential environmental impacts. Interestingly, although photovoltaic electricity grid parity is currently attainable only with subsidies, Fthenakis points out that the nuclear, oil, and gas sectors were subsidized to much larger extents during their development. As an example of the tangled web that often emerges from sustainable-development analysis, Fthenakis suggests that, if the high external health costs associated with the use of coal are taken into account, photovoltaic technology is already economically competitive with fossil-fuel power generation. Such debates will continue - it is the nature of the interconnectivity of the sustainable development field.

Coal is destined to

Energy production enjoys a central position under the sustainability tent. remain a crucial power source for at least the next 50 (or maybe 100?) years, ${ }^{9}$ until sustainable sources of energy become a larger part of the global energy portfolio. About $45 \%$ of electricity in the United States is generated in coal-fired power plants, ${ }^{8}$ because of the local abundance of coal and extensive experience with the technology. In addition, the two most populous countries, India and China, have been building new coal-fired power plants every year at an astounding rate. ${ }^{10}$ The article by Espinal and Morreale addresses one aspect of clean coal technology, namely, carbon mitigation. The major challenge in carbon mitigation, which includes capture, transport, and sequestration of carbon dioxide, is the development of cost-effective, technologically compatible, and efficient carbon dioxide capture and storage technologies. Several opportunities are available for leveraging the field of materials science to manage carbon dioxide, most notably the development of advanced solid-state sorbent media for capture. Carbon mitigation is a thorny political issue not only because carbon dioxide is a greenhouse gas implicated in global warming, but also because its implementation will necessarily raise the cost of electricity.

Finally, water is a major sustainability issue not least because of the key role that water plays in energy production. Specifically, thermal modes of power generation (for example, fossil fuel, nuclear, biomass), in which electricity is generated from heat through a thermodynamic cycle, account for almost $80 \%$ of total generating capacity. In each of these processes, lowgrade waste heat is rejected to the environment, most effectively by use of water-based methods. Thus, the article by $\mathrm{Ku}$ and Shapiro speaks to the demand for cooling water in the energy community. Increasing the thermal efficiency of power plants is one way to reduce their water demand, and materials advances can play a large role in this arena. For example, the key materials challenges for improved gas turbine efficiency are lower-cost superalloys and robust thermal barrier coatings that can allow operation under extremely hot operating conditions (typically $>1300^{\circ} \mathrm{C}$ ). Further, solid-oxide fuel cells can be combined with gas turbines or other engines to achieve even higher thermal efficiencies, further reducing the cooling water requirements.

Revised curricula for materials science and engineering education are critical, because, as fittingly stated by one of this issue's authors, materials scientists and engineers can "make a world of difference by making our world different."11 The article by LeSar et al. emphasizes that sustainable development is a relatively new topic in university engineering curricula, and educators are only in the early stages of teaching this broader view of engineering. Going forward, materials researchers must be taught to think beyond the current definition of what constitutes the "best" material for a given application; their decisions will need to be informed by the topics represented in this special issue: resources, life-cycle assessment, energy and carbon footprints, toxicity, and more.

These brief descriptions of the articles in this special issue are meant to whet the reader's appetite for the in-depth versions that follow. It should be clear that there is something in this issue for every materials professional and interested citizen-scientist, given the breadth of the space at the intersection of materials science and sustainable development. Please contribute - our planet needs lasting solutions.

\section{References}

1. Report of the World Commission on Environment and Development: Our Common Future (Annex to Document A/42/427, Oxford University Press, Oxford, UK, 1987).

2. J. Elkington, Cannibals with Forks: the Triple Bottom Line of 21st Century Business (Capstone Publishing, North Mankato, MN, 1997).

3. S. Sim, M. Barry, R. Clift, S.J. Cowell, Int. J. Life Cycle Assess. 12 (6), 422 (2007).

4. MRS Bull. 33 (4) (2008).

5. T. Dietz, E. Ostrom, P.C. Stern, Science 302 (5652), 1907 (2003).

6. D. Richards, G. Pearson, Eds., The Ecology of Industry: Sectors and Linkages (National Academies Press, Washington, DC, 1998).

7. P. Collier, C.M. Alles, Science 330 (6006), 919 (2010).

8. "Electricity Explained: Electricity in the United States" (U.S. Energy Information Administration, Washington, DC, 2011), www.eia.gov/energyexplained/index. cfm?page=electricity_in_the_united_states (accessed February 2012).

9. S. Ansolabehere, J. Beer, J. Deutch, A.D. Ellerman, S.J. Friedman, H. Herzog, H.D. Jacoby, P.L. Joskow, G. McRae, R. Lester, E. Moniz, E. Steinfield, J. Katzer, The Future of Coal: An Interdisciplinary MIT Study (Massachusetts Institute of Technology, Cambridge, MA, 2007).

10. L. Friedman, "China, India Could "Lock" World in a High-Carbon Energy System, IEA Warns," Scientific American (10 November 2011), www.scientificamerican. com/article.cfm?id=china-india-could-lock-wo (accessed February 2012).

11. D. Apelian, JOM 62 (4), 8 (2010).

12. R.M.K. Yamaji, Y. Nagata, Y. Kaya, in Workshop on $\mathrm{CO}_{2}$ Reduction and Removal: Measures for the Next Century (International Institute for Applied Systems Analysis, Laxenburg, Austria, 1991).

13. M.R. Raupach, G. Marland, P. Ciais, C. Le Quere, J.G. Canadell, G. Klepper, C.B. Field, Proc. Natl. Acad. Sci. U.S.A. 104 (24), 10288 (2007). 
Materials for sustainable development is a scientific concept that globally balances use of the Earth's materials and energy resources, a profitable industrial economy, and availability of affordable materials and products to raise the standard of living.
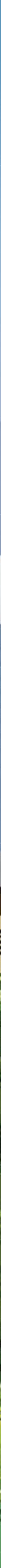